\title{
THE HORROR OF THE REAL: Filmic Form, The Century, and Fritz Lang's $M$
}

PETER GAVARIS

ear the end of The Century, Alain Badiou comes to the conclusion that "the art
of the century inscribed itself paradigmatically between dance and cinema." He never explains this development explicitly, though it can be reasoned that he arrived at this conclusion through a consideration of the immediacy inherent to the nature of both forms. Evidently, dance and cinema share a fixation on dynamic movement, and for Badiou, this distinguishes them from everything that came before, especially since the century "violently declares the present of art." In what follows, I will focus specifically on cinema and the cinematic role as the essential art form of Badiou's century. I will begin by considering why film has been taken up by so many contemporary theorists, examining why the medium (seemingly defined by its constitutional conundrums) lends itself so easily to analysis, and conclude with a consideration of Fritz Lang's $M$ (1931), a film that embodies many of the central ideas presented in The Century.

Cinema, from its conception at the end of the nineteenth century, differentiated itself first and foremost by the way it was to be consumed. Unlike reading a book or looking at a painting, the act of watching a film always involves something of a

1 Badiou, Alain. The Century, trans. Alberto Toscano. Malden: Polity, 2008, p. 160.

2 Badiou, The Century, 135 
power dynamic in the way that it strips the viewer of autonomy. We cede all control when we enter the dark room, look up at the bright screen, and gaze as images unremittingly flash before us until the credits roll. Conversely, we choose the pace at which to read a book; we can deliberate over certain words, re-read pages, and put the book down whenever we want. The same could be said of looking at a painting, since the act still leaves us with our autonomy. We can look away whenever we want, and the canvas is fundamentally static. Given this essential difference, cinema aligns itself much more obviously with theatre, performance art, and dance, as Badiou points out. These art forms originate from movements in a setting that requires us to relinquish control and from the construction of resemblance to our lives. This act of replication, whether it be naturalistic, expressionistic, or anything in between, is just that. Apart from being far more democratic than theater or dance, film differentiates itself from these other forms in that its replication of life has greater potential for resembling life as it is, and duly, bears greater potential for abstraction. Rather than watching the action play out in front of us with the naked eye-as is the case with these other forms of performance-cinema necessitates further layers of construction (and artifice) that are communicated by a director's shot selection, the editing of scenes, among other things. When writing on film, Walter Benjamin observes: "The camera intervenes with the resources of its lowerings and liftings, its interruptions and isolations, its extensions and accelerations, its enlargements and reductions. The camera introduces us to unconscious optics as does psychoanalysis to unconscious impulses." 3

These "unconscious optics," as Benjamin puts it, come about through the dissonance between cinema's base artificiality and its potential for capturing life in motion. Consider the early Lumière films that attempted to do just this. The Arrival of a Train (1896) is simply what its title implies (see Figure 1). Yet, it is much more than just that, since, as Benjamin put it, "filmed behavior lends itself more readily to analysis because of its incomparably more precise statements of the situation [...] it can be isolated more easily." "The same cannot be said for any other artistic form, even those that are movement-based, because it is the camera that imbues an image with meaning by subtracting something from it. Life is at once imitated, and thusly, removed (indeed, Benjamin would likely argue that "the aura" is that which is being removed). Even in shooting life as it is (say, a train arriving at a station), the camera adds an unquantifiable number of variables to the equation: the shot angle, the shot length, the exposure, to name a few. These variables create a specific, irreplicable image for the camera frame. It is the frame itself that further complicates things. In many ways, shooting a film is an act of profound exclusion, since a shot is defined not only by what is in the frame, but also by what is excluded. A shot of a train

\footnotetext{
3 Walter Benjamin. "The Work of Art in the Age of Mechanical Reproduction." The Norton Anthology of Theory and Criticism, ed. Vincent B. Leitch. W. W. Norton \& Company, Inc., 2001: 1181.

4 Benjamin, "The Work of Art in the Age of Mechanical Reproduction," 1180-1181.
} 
arriving at a station implicitly asks us to consider what is occurring outside of the frame. Therefore, the frame is at once finite-and infinite-and this constitutive contradiction lies at the heart of the medium, which makes film the definitive art form of the century, and an object of curiosity for theorists like Benjamin and Badiou.

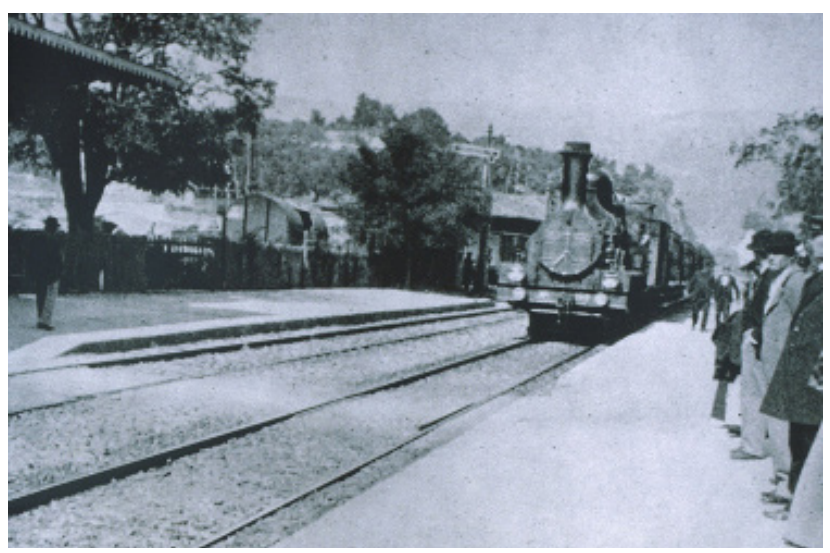

Figure 1

Badiou takes up Cinema's infinite finitude in his chapter on "The infinite." For him, cinema is almost deceitfully deceptive in its promise of showing us life as it is, and the harsh reality that the medium's replication of life is wholly artificial. After all, what is cinema other than a series of still images flashed quickly before us in such a way as to imply movement? In any case, Badiou's conception of the Real, which he correlates to the infinite, can never be replicated in art, including cinema: "The torment of contemporary art in the face of the infinite situates it between a programmatic forcing that announces the return of romantic pathos, on the one hand, and a nihilistic iconoclasm, on the other." ${ }^{5}$ Cinema is situated nicely at this crossroads, as I've explained, because it seems almost to hold these two conflicting ideals (a "romantic pathos" and a "nihilistic iconoclasm") at once, in that its infinite quality only comes about in its shear finitude. Every shot is utterly unique and cannot be replicated perfectly; yet, the shot's artificial construction allows for said uniqueness. Consciously or otherwise, every film carries with it this inherent contradictory, romantic promise of the infinite, which arises from its own formal limitations, as Badiou acknowledges: "The infinite is not captured in form; it transits through form [...] finite form can be equivalent to an infinite opening." "Since the film's form loudly announces its own ineptitude, we are pointed to this infinite opening more frequently than when engaging with other artistic forms.

5 Badiou, The Century, p. 155.

6 Ibid., p. 155. 
In exploring the dichotomy between art's "romantic pathos" and "nihilistic iconoclasm," Badiou spends noticeably more time addressing the latter, focusing on how the "art of subtraction" renders the medium inoperative. (This exemplified by his lengthy analysis of Malevich's White on White.) Admittedly, art can function as a study of surfaces, critiquing its own medium while also incorporating narrative elements and interiority. As discussed, cinema intrinsically seems able to hold these two contradictory elements at once. Badiou's reluctance to take up film as an "art of subtraction" that does not inherently eschew interiority is somewhat disappointing. With that, this essay will henceforth attempt to amend this fact by applying a Badiousian reading to $M(1931)$, a film that succinctly embodies much of the theory presented in The Century.

A far cry from the early cinema of the Lumière Brothers, Fritz Lang's $M$ is one of heightened drama and hyperstylization, featuring exquisite sets, ostentatious camerawork, and dynamic performances. $M$ s formal qualities belong to the German Expressionist movement. Founded on the basis that abstraction could better emulate a sense of interiority than strict, naturalistic representation, expressionism draws attention to itself as artificial (and it makes perfect sense that a form predicated on artificiality would take up abstraction in such a way as to carve out a greater opening for the Badiousian Real to transit through). Ms expressionism seems far from the art of subtraction that Badiou discusses in The Century, and yet, it arrives at a similar impasse. Expressionism and film go hand in hand precisely because cinema is expressionistic in nature, and Lang's film embodies this synthesis, as the apparent, meticulous construction of its images gives way to a newfound interiority.

Wedged between two world wars, $M$ appears to present itself as a procedural, almost rudimentary, crime thriller about a string of child murders, before revealing itself to be an eerily prophetic critique of a society ready to embrace totalitarianism. The mystery of the story is not so much about the identity of the killer-who we learn early on is Hans Beckert (Peter Lorre) — but is rather about the lengths to which the residents of Berlin will go to capture him. Lang commits to highlighting the interconnectedness of the "society of the century," showing how seemingly everybody (from the police force, to the crime bosses, and even the beggars) is working to get this man for a smattering of different and self-serving reasons. By the end, the crime bosses, helped by regular residents who form a sort of citizens' tribunal, capture Beckert. They conduct an unfair trial and commit to killing him before the authorities rush in to break up the party. All this comes after Beckert gives a rousing monologue as the tortured killer, expressing in between shrieks and screams the compulsivity of his actions in a surprisingly affecting call for sympathy. This climactic sequence of the citizens' trial and Beckert's pleading marks a key moment in the film where Lang pulls the wool from our eyes and turns the table on the residents of Berlin (see Figures $2 \& 3$ ). Badiou argues that war and extreme violence in the century come as 
a result of passion for the Real: a stark idealism that requires violence before peace. In what will follow, I aim to argue that this passion for the Real is not manifested in Beckert's compulsive kills, but is rather embodied in the citizens' desire to "put [him] out of commission." For the film's residents of Berlin, the Real can only be actualized by exterminating this evil from within their own society. When outlining his method for approaching The Century, Badiou explains that he wants to examine "how the century thought its own thought." I wish to do the same by considering Lang's film as an artifact of the century, a work of profound self-diagnosis that will provide further insight into how the century thought of itself.

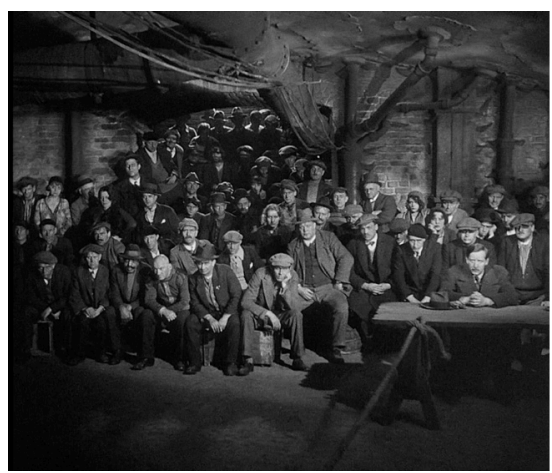

Figure 2

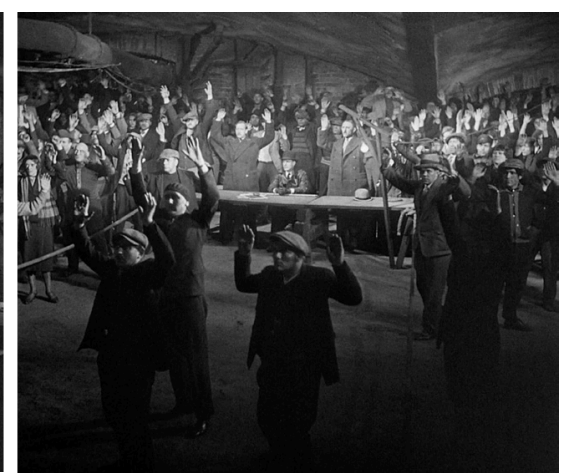

Figure 3

In The Century, Badiou seemingly co-opts the Lacanian Real to refer to that which is unsignifyable: "representation is a symptom (to be read or deciphered) of a Real that it subjectively localizes in the guise of misrecognition." The Real, as conceived of, and explained by, Badiou, refers to a plane of perfection that is perpetually out of reach, separated from us by a gap. Nonetheless, this passion for the Real inspires the destruction, subtraction, and formalization that seem only to manifest in either art or violence. Idealism, more than anything else, becomes the driving force behind this passion for the Real since the passion itself comes from a belief that the gap between semblance and Real can be transcended. Badiou explains this idea in relation to Nazi thought before concluding that "passion for the Real is devoid of morality [...] extreme violence is therefore the correlate of extreme enthusiasm." 10 It, therefore, becomes paramount to acknowledge that Nazism, or any other form of oppressive regime, bears an ideology. As horrific as it may sound, it is a fundamental optimism - that of attaining the Real - that accounts for so much violence in the century that Badiou claims is defined by its passion: "Bad violence must be followed

7 Lang, $M$.

8 Badiou, The Century, p. 3.

9 Ibid., p. 49.

10 Ibid., p. 63. 
by good violence, which is legitimated by the former [...] the good war will put an end to the bad war." ${ }^{11}$ In turn, it makes perfect sense to view Berlin's residents' totalitarian, self-serving desire to kill Beckert as a passion for the Real.

Surely, the perversity of the situation manifests itself in the simple fact that the residents of Berlin are acting reasonably — at least initially_-when it comes to their desire to catch Beckert (since he represents a legitimate threat to their society). Their crusade, their "just war," is justifiable up until the point at which society collectively decides that Beckert is less than human and undeserving of justice. This almost casual change in mindset has profound consequences, as Badiou explains, in that it accounts for much of the violence of the century: "the century's Real problem is to be located in the linkage between 'democracies' and that which, after the fact, they designate as their Other [...] What needs to be undone is precisely this discursive procedure of absolution." 12 The film's title refers to the chalk letter "M" (for murderer) slapped onto Beckert's back at one point in the film (see Figure 4). This moment holds significant import in that it represents the moment when Beckert is explicitly made to be Other; he becomes the target. The citizens, in turn, find no issue in making Beckert the ostensive Other in accordance with the belief that his elimination will allow for a lasting peace: "The twentieth century's idea of war is that of the decisive war, of the last war." ${ }^{13}$ It is this stark optimism — and an inability to see beyond the present moment and situation-that allows for this sort of barbarous, ideological collective consciousness to take shape.

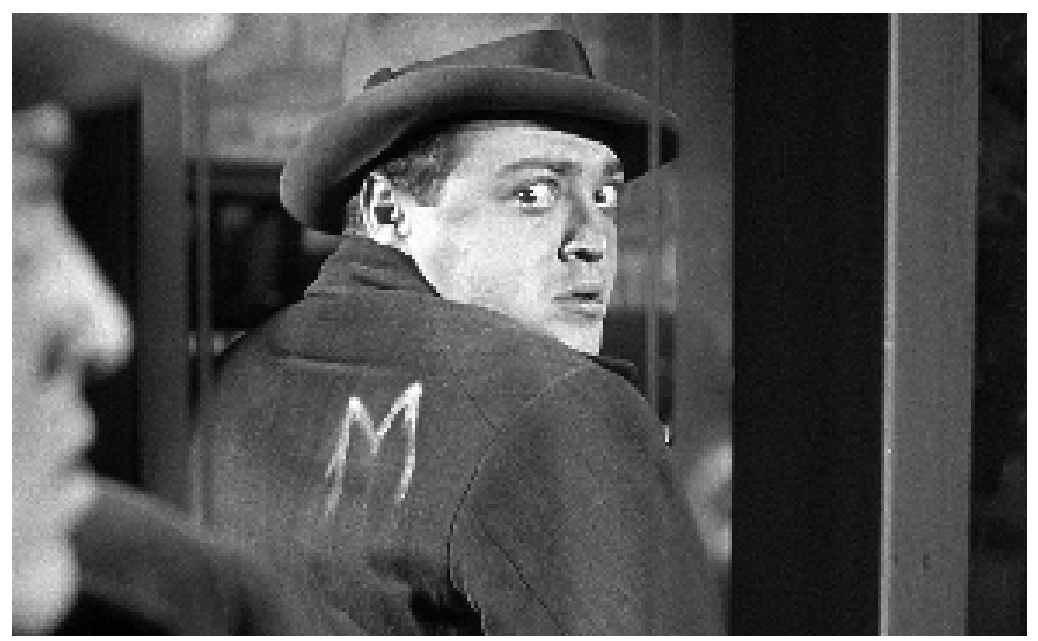

Figure 4

11 Ibid., p. 30.

12 Ibid., p. 5.

13 Ibid., p. 34. 
Lang effortlessly makes us aware of this shifting subjectivity through the use of cinematic techniques that informs our internalization of the narrative. Notice, for instance, the way most of the action is staged throughout the film. The scenes where Beckert is being chased through the streets are shot using high-angle long shots (see Figure 5). Shots of this kind emphasize the smallness of these characters, making them appear almost like pawns in a game as they chase each other down corridors and dark alleys. The camera shoots them at a distance to represent the metaphorical distance established between these characters and the viewer. By the film's conclusion, Lang closes this distance, through his use of close-ups, in order to evoke our sympathy for this character. If the long shots before were meant to imply distance, then these close-ups, like the famous one of Beckert pleading (see Figure 6), are meant to elicit empathy and imply interiority. Writing on the close-up shot, Benjamin concludes: "With the close-up, space expands [...] the enlargement of a snapshot does not simply render more precise what in any case was visible, though unclear: it reveals entirely new structural formations on the subject." ${ }^{14}$ Surely, the power of the film's ending comes in our acknowledgement of the newly discovered structural formations of Beckert's character. Notable, too, is the fact that we can only collapse this emotional distance as Lang does in film: live performance cannot replicate the cinematic freedom that comes with using a camera.

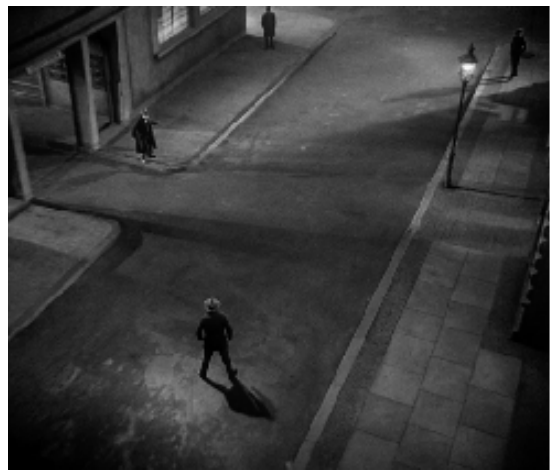

Figure 5

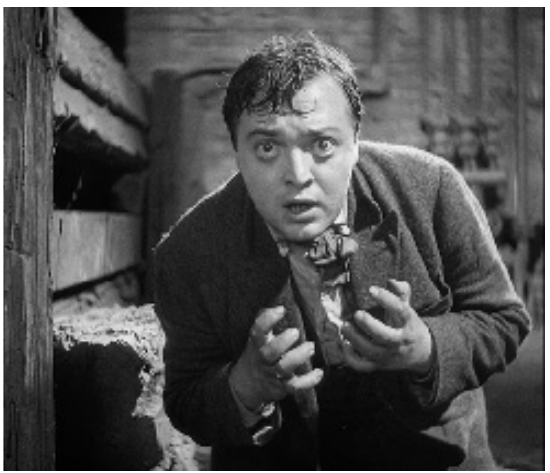

Figure 6

Adding to the novelty of $M$ is the fact that the crime bosses, and not the police, mastermind the plan to capture and to try Beckert's. We come to realize that the heightened police activity_-brought about by Beckert's killings — thwarts the city's criminal activity. In laying down this groundwork, Lang sets up a strange sort of hierarchy wherein the police hold power over the criminals and the criminals hold power over Beckert. They resort to a dangerous kind of absolution in the end, which

14 Benjamin, "The Work of Art in the Age of Mechanical Reproduction," p. 1181. 
Badiou vehemently warns against when writing on Nazi ideology. He disapproves of those who simply consider Nazism unthinkably evil, since this inability to acknowledge ideology (or interiority) often results in even more violence and horror. Badiou explains: "To maintain that Nazism is not a form of thought, or, more generally, that barbarism does not think, is to abet a process of surreptitious absolution." ${ }^{15}$ We see this surreptitious absolution in the sheer cruelty of the criminals and other residents of Berlin who put Beckert on trial, and who laugh and jeer at the killer as he begs for his life. In a strange way, Lang's directorial method asks us to consider this killer's thought — that is, to assume a basic sort of interiority. Badiou writes of wanting to know how the century thinks of itself, and Lang's film almost seems to want to achieve the same thing. $M$ not only thinks about the century, but it also goes further to criticize it in the midst of its happening.

The "surreptitious absolution" taken up by the residents of Berlin represents how ideology becomes collective, and, evidently, political. In $M$, passion for the Real is addressed and brought to life by groups of smarmy men in smoke-filled rooms: the crime bosses, and also the police chiefs (see Figure 7). Ideology, under the guise of politics, forms amidst the few before it is promulgated to the masses. The central dichotomy, that between the thinking, ideologically protected residents and the barbarous Beckert, is achieved through this absolution and enforced by the simple, undeniable fact that politics thinks itself just. A lone killer cannot have an ideology — or any sort of interiority — whereby a group of likeminded residents must be justified in their thinking since there are so many of them. Badiou confirms this very suspicion: "Politics, when it exists, grounds its own principle regarding the Real, and is thus in need of nothing, save itself." ${ }^{16}$ Evidently, passion for the Real acts both as a justification for a genuinely barbarous ideology, and as a way to self-legitimatize that which wields power. Politics is self-serving, and this point is made explicit by the fact that those condemning Beckert are, themselves, criminals too!

This propensity of politics to "save itself" calls to mind Giorgio Agamben's theory of 'bare life,' whereby a sovereign-power must exclude_-deem worthless_-some other form of life in order to maintain its own hegemony: "[the] living being who, though being human, is excluded-and through this exclusion, included-in humanity, so that human beings can have a human life, which is to say a political life." ${ }^{17}$ Though, it's unclear if Agamben's exclusive inclusivity of the sovereign-power/bare-life dichotomy requires bare-life to exist. Is Beckert 'bare life' if he is to be killed? Even in death, does he live on as an emblem of the Agambenian homo sacer for the politically minded residents of Berlin? History mournfully reminds us that many of these same Germans would find a new form of 'sovereign power' in the decade to follow. Either way, in

15 Badiou, 4.

16 Ibid., p. 6.

17 Agamben, Giorgio. The Use of Bodies. Edited by Werner Hamacher. Translated by Adam Kotsko, Stanford University Press, 2016, p. 23. 
attempting to synthesize Agambenian and Badiousian theory, looking at Lang's film through the lens of both, I extrapolate a few notable points. First, I argue that this passion for the Real is a justification — a kind of moral imperative-for Agambenian 'bare life.' We can also determine that the specifics of 'bare life' as described by Agamben, life whose biological existence is considered worthless, applies to Badiou's thoughts on politics. Do all politics and ideologies subsist on rendering the Other as homo sacer?

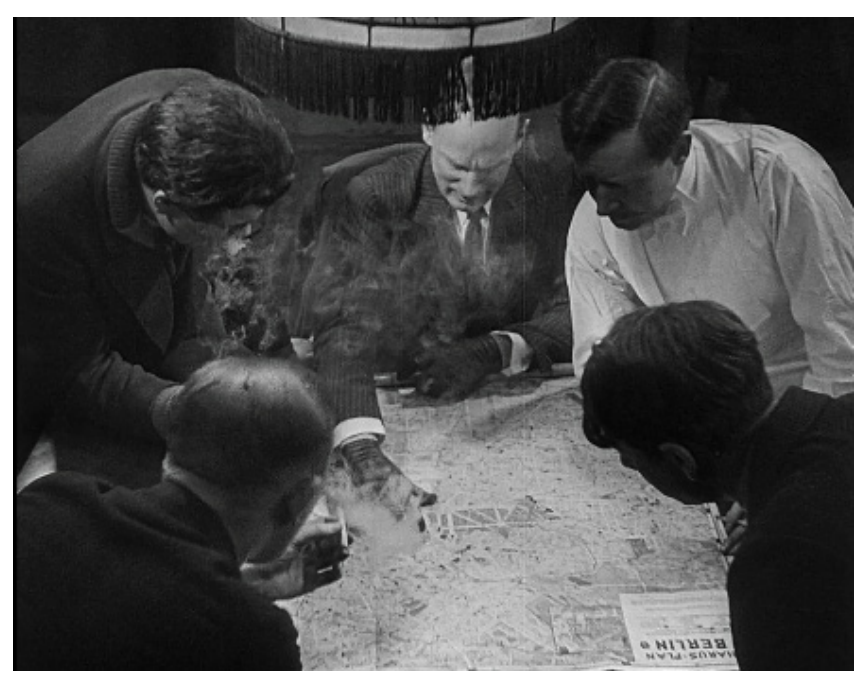

Figure 7

Badiou surely overlooked $M$ because its expressionist sensibility flies in the face of the 'art of subtraction' that he champions in The Century. And while his points on subtraction (the art of auto-interrogation) are made clear in the text, there remains something to be said about more mainstream art that still manages to interrogate these aspects of society. The closest $M$ gets to modernism is in its jagged construction, which comes from its constantly shifting perspective, oscillating from the crime bosses, to the beggars, to Beckert, to the police, and back again. Take that as you may, but there is something tragic about the fact that Lang's film was widely seen-largely championed - and yet, failed to make the country of its origin aware of its demons. If Badiou is correct in postulating that passion for the Real manifests in the disjunctive synthesis between art and violence, than $M$ proves, more than anything else, that this violence may overpower its artistic correlate. 


\section{BIBLIOGRAPHY}

Agamben, Giorgio. The Use of Bodies. Edited by Werner Hamacher. Translated by Adam Kotsko, Stanford University Press, 2016.

Badiou, Alain. The Century. Translated by Alberto Toscano, Polity, 2008.

Benjamin, Walter. "The Work of Art in the Age of Mechanical Reproduction." The Norton Anthology of Theory and Criticism, edited by Vincent B. Leitch, W. W. Norton \& Company, Inc., 2001, pp. 1166-1186.

Lang, Fritz, director. M. Nero-Film A-G, 1931. 